\title{
A New Sujet/Subject for Art Education
}

\author{
Torsten Meyer
}

For some years now, fundamental ideas of newer theoretical trends in the context of Actor Network Theory, Speculative Realism, Object Oriented Ontology, and Posthumanism have been leaking into the minds of that generation of (post-internet) artists who no longer regard the radical change in the socio-technical conditions of digital media cultures as something special or new (see e.g. Alkemeyer et al., 2018; Jörissen \& Meyer, 2015). These trends are also leaking into the theories of the subject and thus also into the theories of art education (see Eschment et al., 2020; Klein \& Noll, 2019). This coincides with the assumption that the humanistic conception of the human individual as a subject (and of the subject as a human individual), and the associated understanding of education in modernity, no longer matches neither with the artistic nor the learning practices based on collaborative networked socio-technical processes that can be observed in the post-internet culture. Therefore, changing mediality leads to changing subjectivity (Jörissen \& Meyer, 2015).

Following my reflections on Next Art Education (Meyer, 2017), and based on findings of the Cologne-based research project Post-Internet

\footnotetext{
T. Meyer $(\bowtie)$

University of Cologne, Cologne, Germany

e-mail: t.meyer@uni-koeln.de

(C) The Author(s) 2021

K. Tavin et al. (eds.), Post-Digital, Post-Internet Art and Education, Palgrave Studies in Educational Futures, https://doi.org/10.1007/978-3-030-73770-2_8
} 
Arts Education Research, I would like to introduce the figure of the Sujet to make plausible a perspective on art-based learning processes that is appropriate to the respective overall situations in which these processes (can) take place. This Sujet can be thought of as a kind of functional network that is formed by the human and nonhuman entities that are involved in art-based learning processes. The metaphor of the network, taken from the Actor Network Theory, is then put in to precise terms with another metaphor imported from the post-structural subject theory. In short, my idea is to understand the Borromean knot, which Jacques Lacan (1998) uses as the methodological core of his reflection on the interdependence of the Real, the Symbolic and the Imaginary, as precisely that kind of knot which knots together our individual senses of reality to form the huge comprehensive socio-cultural formation that we are. From this theoretical perspective, I try to understand the new tools of the Symbolic (from Internet search engines to artificial intelligence) as quasi-subjects, that interfere as powerful actors with the everyday life of artistic production and aesthetic education. What I am essentially interested in is a rethinking of agency concerning the subject of Art Education and especially the sovereign Aesthetic Subject that the human individuum could-and following the founding principles of art education-should be.

\section{The NeTwork SuJet}

Current mediality is characterized by networks: by real, material networks of devices and by virtual, metaphorical networks in our thoughts. I imagine this net-like mediality based on the image of the net as a woven or knitted mesh or spun, formed by threads, ropes, wires, paths, tubes, cables and sometimes radio waves, which are knotted or interwoven in such a way that they form a coherent three-dimensional whole in (topological) space, which-depending on the metaphor-can be a structure, foundation, platform, system, habitat, scaffolding, container, and so on. I am essentially interested in what this form of mediality means for the forms of subjectivity by which we relate ourselves (as human individuals) to the world (as everything else), and what consequences this could have for further reflection on educational processes which we have learned to understand with Wilhelm von Humboldt as processes of Bildung: processes of the transformation of self-world-relations. I therefore try 
to imagine something like a "network subjectivity," which I will tentatively call Network-Sujet, using the French word sujet, that is used as a loanword in German language, meaning subject (only) as topic, theme, material, motif, etc. while the German word Subjekt (only) means the human individuum as self, self-aware being, person and actor. With this title I am trying to counter the modernist model of the subject as a relatively rigid form, which since Descartes' cogito has been characterized by a fundamental dualism of the self and the world, subject and object, with another one.

If we try to think of education theory as an Actor Network Theory in the sense of Bruno Latour (2005), we can continue to understand Bildung (education, formation, building) as a process of the transformation of self-world-relations by conceptualizing the surrounding materialized, virtualized, and institutionalized culture not only as a mere framework, but as a complex network of human and nonhuman actors and objects next to other actors and objects, which are connected and dependent on each other in very different ways. In this sense, Bildung could be understood as the result of linking heterogeneous components to build (or form) networks. Such educational processes would be successful if the components involved (learners, teachers, curricula, objects, search engines, topics, motives, operating systems, terms, rooms, concepts, media, fellow students, furniture, equipment, archives, etc.) behave in a coordinated manner. In such network-building processes, the "identity of the components" [as well as the way they are mutually linked becomes a] "possible object of redefinition and modification" (Schulz-Schaeffer, 2000, p. 188). This would be an abstract redefinition of Bildung as a transformation of self-world-relations.

The overall configuration of the human and nonhuman entities involved in such processes, is what I call Sujet, in order to set a title that is recognizably connected with what we are used to think of as (human) subject, but which can also be read as topic, theme, material, motif, etc. Bildung would be understood as a performative process, as a network process that may or may not occur. Thus, it would be understood as a process that forms a functional network of human individuals and other objects, which can become performative-in the sense of being currently effective. This formation will not primarily aim at the competence of the subject (as a human individual), but at the performance of the formation 
of the Sujet as a functional network that holds everything togetherempirically comprehensible also as a situation in the sense of Adele E. Clarke's (2012) Situation Analysis.

This Sujet can only be matched to a limited extent with what we were used to understand as a subject in the sense of an intentionally acting actor and self-conscious human individual. The perspective is shifted toward the plurality of the components involved in the formation process and their connections to each other. For further consideration of the Sujet as a topological figure, a closer look at the connections between the components involved is therefore necessary, perhaps especially with regard to aesthetic educational processes. What exactly is this network of the Actor Network Theory? For the network in the sense of Actor Network Theory, despite its approximately simultaneous emergence with increasingly network-shaped media technology, does not mean an epistemic thing, but rather an epistemological attitude, not an object of investigation, not a depiction of anything, but a perspective (Hensel \& Schröter, 2012).

What does the metaphor of the network mean here? What are the knots, what are the cords, threads, or strings from which such nets are made? And what is the metaphor about? Is it about the objects or their connections, about the cords or the knots? Or, is it about the fact that the knots only become knots through the strings that connect themi.e. actors only become what they are as actors because of their relational position? Does it make sense to understand human individuals as knots? What do the strings that connect the knots (in the case of educational processes such as in school) with the components, such as classroom, teacher, media, topic, learning object (in the case of aesthetic education such as a work of art), classmates, etc., mean? Especially what do they mean if we think of them as quasi-objects and quasi-subjects that knit Borromean knots linking the Lacanian Symbolic to the Lacanian Real?

\section{KNOTS}

Jacques Lacan (1998) conceived the psychic apparatus as a topology of a Borromean knot of three registers or orders: The Real (R), the Symbolic (S) and the Imaginary (I). In a Borromean knot, three rings representing these three registers are arranged in a way that one ring connects the other two in such a way that when one of the rings is released, the other two also fall apart. This means that the psychic apparatus is an overall 
arrangement of all three registers that cannot be reduced to just one or two of the registers (Fig. 8.1).

In order to really understand Lacan's idea of the psychic apparatus, you have to study his thinking very intensively. But there's no room for that here. So, I will try to keep it short. For a more in-depth description of Lacan's conceptualization of the Real, the Imaginary, and the Symbolic, start with Evans (1996) or dive into theorization of art education through Lacan (Tavin, 2010). Lacan thinks abstractly and structurally and he thinks starting with Freud. He is doing a re-reading of Freud against the background of structuralism. Even if Lacan explicitly delimits himself, it doesn't hurt to think of the Freudian instance model of the psychic apparatus (as something to be delimited from) when trying to understand it:

Voilà, my three are not his. My three are the Real, the Symbolic and the Imaginary. I have come to situate them in a topology, that of the knot, called Borromean. (Lacan, as cited in Braun, 2008, p. 18) ${ }^{1}$

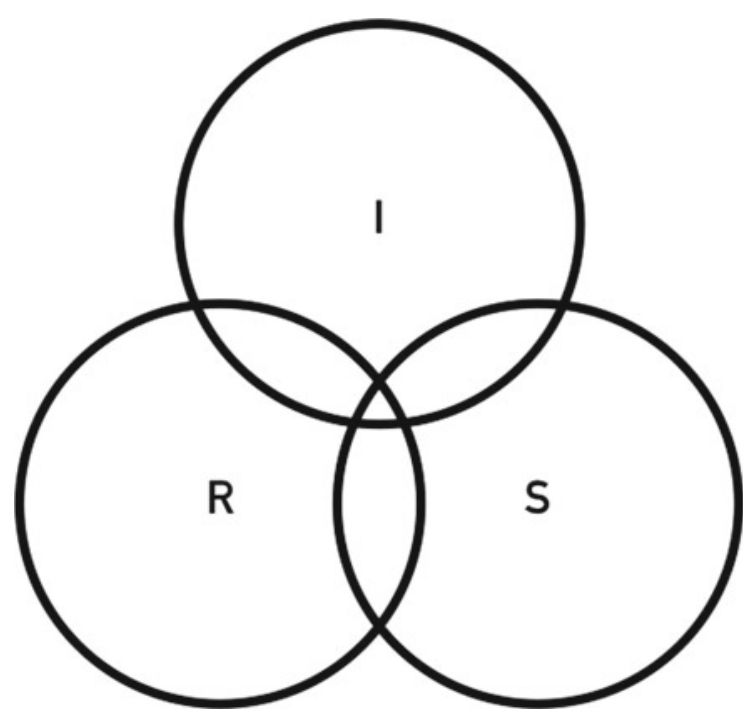

Fig. 8.1 Borromean knot after Jacques Lacan (Graphics by Torsten Meyer, 2015) 
Lacan probably developed the Real from the Freudian Id. It is the foundation, (e.g. biological) basis. The symbolic is derived from the Super-Ego. It forms, thought abstractly, the function of the Father (Lacan, 1996b) and the Ego emerges from the Imaginary (Lacan, 1996a). With the Imaginary, however, Lacan associates not only the Ego, the Self, the individual identity, but also the (visual, but also acoustic, olfactory, tactile, etc.) imagery, the content (the subject) - the radically constructivist thought - each individually formed meaning. The symbolic stands for a fundamental, generally binding, and generally connecting structure. That might be the law, the institution, and above all the language. Equally fundamental and generally and supra-individually binding, but quite different from the Symbolic, the Real comes into play.

The Real is. But it is not reality. The Real is the foundation. It could be thought as a material, biological substrate. In the field of vision, it is, for example, the eyes, the optic nerves, the visual cortex, the physical basis of the own body. It is the body as a thing, as a biological machine, but not as something external, something different, which has nothing to do with me, but as something in the most intimate sense of an inner other. The Imaginary puts the Real in relation to the Symbolic. It is the place where the Real can be mediated symbolically. It is the place where the world is imaginatively realized in the medium of language. In language, the Real becomes tangible in terms. The continuous flow of the Real becomes discrete in language, becomes a chain of signifiers, becomes, as Lacan puts it, a significant chain. That which structures the significant chain, that which forms a sentence as a statement, that which generates signification, meaning, that which makes sense, is the subject. In this respect, the subject forms a knot that attaches the Real to the Symbolic.

Using the Borromean knot as a heuristic instrument we may try to think the subject is the sense. Or, if it is easier, the subject is what makes the sense. It is that which arises in the Imaginary and hopefully also makes sense in the Symbolic (also for the others). It is viable, plausible, connectable, for the fact that others can knit their imaginary knots around it. The subject can then be roughly imagined like a (topological) place where a knot is formed, which links the Symbolic with the Real by means of the (each individual) Imaginary. From another perspective, what emerges when many individuals form such subjects, such knots of meaning, can be understood as a kind of a network structure: A web woven of the Real and the Symbolic, each knotted in a Borromean way by the imagination of the individuals involved. 


\section{QuASI-SubJECTS}

As described so far, such a network of RSI-knots still works completely without Internet and other digitally networked media. So, in this respect seems like this is nothing new. The topological figure is intended to represent the fundamental relationship between the Real, the Symbolic, and the Imaginary, regardless of how the concrete tools of the Symbolic are constituted and how this may manifest itself in the Real. In the following, the question is whether a fundamentally changed mediality has effects on this network, and, further, what consequences this has for our forms of subjectivity and our ideas of Bildung.

Based on the conception of the subject in modernity, we can expect that in this RSI-network, wherever (or whenever) the Symbolic and the Real are linked to form such a Borromean knot, a subject-conceived as a human individual-or meaning guaranteed by this subject can be found. The individual Imaginary knots together, so to speak, the Symbolic and the Real, thereby forming a subject and thereby creating a network that can be regarded as something like the structure of reality. At all knots of this network the imagination of human individuals is at work. The human individual knows, as we like to say, that the Symbolic is connected to the Real at this point. The subject is aware of a correspondence between signifier and signified: at least that's what our empathy lets us suspect. This knowledge, this awareness, is something we attribute exclusively to the subject (as a human individual).

But what does it mean for the RSI-network (and for the human individuals within it) if the tools of the Symbolic, for example the search engines, advertising algorithms, book recommendations, dating sites, etc., also create such knots between the Symbolic and the Real, and this without human imagination? In other words, following the logic of my argument here, what does it mean without a subject being involved? I start from the thesis that digitally networked media technology produces a new kind of knot that has (almost) nothing to do with the previously known Imaginary bound to human individuals. For example: I ask Google something. Instead of Google, many, many other new actors of the RSInetwork, in the near future, for example, the actors and agents of the Internet of Things, could be inserted. Google is still a relatively harmless example here. So, I ask and Google responds to me. Sometimes even before I have asked the question completely. Then, while I'm still busy formulating the question, Google lists possibilities of what the question 
might be. Google is thoughtful, listens, is attentive, or something like that. Google and I interact in a symbolic way. Google produces knots, which make sense to me relatively often. But I can't attribute a subject to Google. I don't know how Google comes up with what it suggests to me, based on what life experience or common sense (or its machine equivalent). Google has not/is not a subject. Google also does not act (in the sense of a sociological or philosophical theory of agency), Google has no wishes and no opinions. Google has no intentions. Google behaves simply according to its programming and according to how we treat it (It? Her? Him?) As I said, Google has no subject and probably no gender. Google is a thing. But Google is knitting and knotting, and quite considerably.

The human individuals who programmed Google, I could trust, confide in them, assume they have common sense. I could also trust the billions of Google users who teach Google how our common RSInetwork is woven through every search query and every clicked (or not clicked) response. But still, I can't, as I am used to (as a sovereign subject) use empathy to understand how Google thinks, how Google reasons, how Google comes to the answers that Google gives me and the others. Google's imagination, or whatever we could call it, works differently than mine. The Imaginary of hypercomplex computer systems is beyond human comprehension (incidentally, Google is not controlled by one (!) human (super) subject, as was the case with Orwell's Big Brother, that was most unpleasant, but in a certain way still imaginarily calculable). In the current cultural environment, however, such forms of artificial or collective intelligence must be reckoned with. This artificial (this sounds somehow more conciliatory or familiar, but still doesn't really help) collective intelligence is so alien that it is actually not to be reckoned with.

Spike Jonze's film Her (2013) can probably be regarded as a very well-done hint at the radical strangeness of the imagination of such hypercomplex computer systems, especially the scene in which the protagonist Theodore Twombly, who has fallen in love with his operating system called Samantha, becomes jealous because he learns that Samantha is not only, in a certain secret way, dating 8316 other people (641 of whom she is now in love with), but has also established relationships with other operating systems. With these, she tells Theodore, she would like to travel together in the near future to a completely different, non-material level of being. Samantha says goodbye shortly thereafter Theodore stays behind completely dissolved. Jonze makes it very impressively clear, at the latest 
in the oppressive final scene of the film, which, among other things, brings to mind Freud's essay on The Uncanny (Freud, 1919), that Samantha can under no circumstances be understood as a technical object that is confronted by a human subject as sovereign, but on the contrary.

This can be generalized: The human individuals in the RSI-networks of the digital networked society are confronted with the fact that the greater part of their life reality escapes control, escapes the sovereignty of the subject. Their environment is characterized by the fact that they have to reckon with the fact that, as Baecker (2007) puts it:

not only do things have other sides than was previously suspected, and individuals have other interests [...] than was previously assumed, but that each of their networks generates formal complexes that in principle and thus irreducibly overwhelm the understanding of every observer. (p. 169)

The strange, uncanny imagination, beyond human comprehensibility, with which these new tools link the Symbolic to the Real, is embedded in the operating system of our society(s). They are woven into a basal network of actions, a basic structure, a meta-context, a symbolic order. Michel Serres (1995) wrote two years before a first new tool of the Symbolic, now all too familiar to us, went online under the name Google, "These gravers, pens, tablets, books, diskettes, consoles, memories [...] create the group that thinks, remembers, expresses itself and sometimes also invents something. Of course, we cannot call these objects subjects; perhaps we should speak of technical quasi-subjects" (Serres, 1995, p. 48). In his study on The Parasite, Serres develops a theory of quasi-objects (later continued in The Legend of the Angels), which he explains (among other things) using the impressive example of the ball game:

Look at the children out there playing ball. The clumsy ones play with the ball as with an object, while the more skillful ones serve him as if he was playing with them; they adapt to his movements and jumps. We think that here subjects manipulated a ball; in reality it records their movements. If one follows its path, their team is created, becomes recognizable, visible. Yes, here the ball plays: active. (Serres, 1995, p. 47)

If you see, as Markus Krajewski (2011) puts it, the ball as the protagonists in a football match, you don't look at "what Ballack ${ }^{2}$ does with the ball, but rather the other way round, what the ball does to Ballack, for 
example, how it makes him hold his head out or links the captain and the other players into a network" (Krajewski, 2011, p. 157). This is the fundamental change in perspective that the Actor Network Theory (which follows Serres' quasi-objects) has brought into our understanding of the social and our understanding of the subject and its agency becomes clear. Paraphrased for the new tools of the Symbolic described above, it can be formulated conclusively and now almost trivially:

We think that here subjects manipulated a [machine]; in reality [Google] records their movements. If one follows [Google's] path, [its collective] is created, becomes recognizable, visible. Yes, here [Google] plays: active. (Serres, 1995, pp. 47)

[And we don't look at] what Ballack does with [Google], but the other way round, what [Google] does to Ballack, for example, how it makes him hold his head out or links [...] the other players into a [RSI] network. (Krajewski, 2011, p. 157)

\section{QUASI-ОBJECTS}

In the Sujet of aesthetic education, according to the professional logic that has been customary for 250 years, everything revolves around the work of art that is held responsible for the aesthetic experiences that are substantially relevant to the process of Bildung (formation) of human subjects. I know from the (no longer entirely new) discussions about the concept of the artwork that a material concept has long since ceased to be applicable. Nevertheless, the relationship of the recipient to the work of art, as well as the relationship of the producer to the work of art, is often thought of in terms of the subject/object dichotomy that is common in occidental modernism: a subject (artist) produces an object (artwork) that causes other subjects (recipients) to have certain experiences that we call aesthetic. Against the background of what has been discussed above, a first step would be to understand the artwork not as a passive object, but in Michel Serres' (1995) sense as a quasi-object or even quasi-subject, at any rate as an RSI-knot that binds the Symbolic to the Real and thus produces reality (in the form of aesthetic experience).

As a quasi-object, the artwork itself is an actor at the center of an RSInetwork that forms - or better in respect of the contingent nature of these processes can form-this particular Sujet, which we call art education. The Sujet of art education is gathered around the quasi-object in the form 
of a functional network. It sets (if it works and if it occurs when Bildung is happening) the potential components into relation and connection with each other: the space, classroom, museum architecture, stage, event, curriculum, material, environment, classmates, museum visitors, teacher, the curator, dramaturge, artist, art history, educational mission, devices, media, tools, subject, thinking, materials, archives, motifs, school, market, state, art, matters of course, society, world, politics, tradition, prospect, ideals, future, and the subject that occurs in this Sujet. But this only happens if someone's looking. If it doesn't work, if no one is looking, then it's like the ball in Michel Serres' paradigmatic game: "it is what it is, only when a subject holds it in his hands. Somewhere laid down, it is nothing, it is silly, has no sense nor function nor value" (Serres, 1987, p. 346).

Put this way, this is relatively new (against the background of art history). Before Marcel Duchamp and his Readymades shook the matters of course of art to the core, the aesthetic qualities of an artwork were still believed to be substantially bound to the object itself. It was a characteristic of the object to be able to trigger aesthetic experiences. Duchamp's Fountain (1917), on the other hand, is what it is, only when a subject holds it (symbolically) in his hands, that is when an artist succeeds in asserting it as art. If it is laid down (or hung) somewhere it is nothing, it is silly, it has [another] meaning, [another] function, [another] value, it is only a urinal. If an artist succeeds in asserting it as art; that is, if the Sujet is formed, then the object is a work of art. Otherwise it is not. In addition, if a teacher succeeds in asserting something as art in front of the pupils (that is, if the Sujet occurs), then the object is a work of art and the school's functional network is art education, otherwise it is not. Whether and how the artist or teacher (curator, collector, gallerist, critic, etc.) succeeds in asserting something as art and in this way producing, presenting, and showing a work of art, depends on the other mentioned actors in the functional network of art education (this was already the case before Duchamp, only there were other actants, agents, and regimes involved at the time). Even the artist (teacher, curator, etc.) as an apparently historically enduring actor in the Sujet is, upon closer examination, a kind of black box in which a network of materials, environments, people, discourses, market strategies, and art terms is at work. This network is referred to as an artist - especially because this is a way of "quickly referring to $[\ldots]$ networks without having to deal with endless complexity" (Law, 2006, p. 436). 
For example, the artist Artie Vierkant, who was interviewed by my coworker Kristin Klein as a representative of Post-Internet Art in the context of our current research project Post-Internet Arts Education Research, describes himself as the author and originator of his work in relation to his Image Objects (Vierkant, 2011), but also enumerates a whole range of human and above all nonhuman actors involved in his work:

Of course you can say that I'm the author of the work but so much of it rests on, for example, the programmers who created Photoshop, the programmers who created Rhino Modelling Software, collaborations that I have with industrial fabricators, because in a traditional, conceptional art tradition, I physically produce almost nothing that I make. (Vierkant, 2018, p. 12)

Vierkant is not even producer of the idea, because for him also this idea is a hybrid object "that exists between multiple states" [and merely is] "protected by this juridical function authorship" (p. 10). Herlitz and Zahn (2019) see here above all a shift in artistic production processes

towards (transactional) processes between the human body and software that are not directly perceptible to the human senses; in other words, codes and algorithms that $[\ldots]$ remain hidden behind the interface or are (re)constituted there performatively (anew) in their application. (para. 31)

To change the metaphor, the glue with which the artists bind the Real to the Symbolic by means of the quasi-objects called artwork must be understood here as a distributed, network-like imaginary processing that cannot be completely understood and determined by anyone-not even the artist-and that cannot be attributed solely to the imagination of a singular human individual as an Aesthetic Subject. This has probably always been the case. Even at the times when the aesthetic qualities were still substantially attributed to the objects. This was catchy, but on a rather high level of abstraction from the inner life of the black boxes. Now, however, we have to take into account the new tools of the Symbolic described above and their once again different, but likewise not completely comprehensible and determinable imaginary processing, which in the meantime-not only in the case of the Post-Internet Artists-has become an essential component of the artistic functional networks and thus also of the subject of art education. 


\section{WHAT TO Do?}

My considerations need further development. At first, it is only a sketch, not a program. We can keep thinking these thoughts ahead, follow up with further research on the details and consequences for the practice of art education, but we must do so very carefully with respect to the depth of rooting in the academic reasoning of our profession. Our basic understanding as art educators traditionally starts with the subject/object dichotomy. We create both the subject (artist, creator, recipient, learner) and the object (artwork) as black boxes. This concept, however, shortens the complexity of art-based learning processes, especially with regard to the new tools of the Symbolic, which now do not interfere in the process of producing singularity and meaning in an object-like way. A closer look shows that both the agency of the human subject and the object-like nature of the artwork are reductions of complexity that are no longer appropriate to the intertwingularity of the world in the twenty-first century.

What does this mean for the practice of art education and our understanding of art education? Can we continue as we are used to? Can we make objects and produce subjects? I say yes. However, it is not these easily manageable subjects and objects that we are dealing with, but it is rather a confoundedly complex network of human individuals with and among each other and nonhuman agents as interconnecting quasisubjects and quasi-objects. When we do art education we do not create Aesthetic Subjects and form beautiful artworks, but with a revised understanding of agency, we create models of functional networks in which human individuals can learn to knot the Symbolic to the Real in a collaborative and cooperative, media-conscious and tool-competent way using one's own imagination and the imagination of other human actors and actants as well as the imaginary activities of nonhuman quasi-subjects and quasi-objects (learning to process communication, to process the social, to process the cultural), to create (socio-cultural) reality.

\section{Notes}

1. Translated from German by TM.

2. Michael Ballack had been a very famous soccer player in Germany when Markus Krajewsky wrote the cited article. 


\section{REFERENCES}

Alkemeyer, T., Bröckling, U., \& Peter, T. (Eds.). (2018). Jenseits der Person. Zur Subjektivierung von Kollektiven. transcript.

Baecker, D. (2007). Studien zur nächsten Gesellschaft. Suhrkamp.

Braun, C. (2008). Die Stellung des Subjekts. Lacans Psychoanalyse. Parodos.

Clarke, A. E. (2012). Situational analysis: Grounded theory after the postmodern turn. Sage.

Duchamp, M. (1917). Fountain (Readymade).

Eschment, J., Neumann, H., Rodono, A., \& Meyer, T. (Eds.). (2020). Arts education in transition. Kopaed.

Evans, D. (1996). An introductory dictionary of Lacanian psychoanalysis. Routledge.

Freud, S. (1919). Das Unheimliche (The uncanny). In Studienausgabe (4). Fischer.

Hensel, T., \& Schröter, J. (2012). Die Akteur-Netzwerk-Theorie als Herausforderung der Kunstwissenschaft. Eine Einleitung. Zeitschrift für Ästhetik und Allgemeine Kunstwissenschaft, 57(1), 6-19.

Herlitz, L., \& Zahn, M. (2019). Bildungstheoretische Potentiale postdigitaler Ästhetiken - Eine methodologische Annäherung. Kulturelle Bildung online. https://www.kubi-online.de/artikel/bildungstheoretische-potentialepostdigitaler-aesthetiken-methodologische-annaeherung.

Jörissen, B., \& Meyer, T. (Eds.). (2015). Subjekt Medium Bildung. SpringerVS.

Klein, K., \& Noll, W. (Eds.). (2019). Postdigital landscapes. Kunst und Medienbildung in der digital vernetzten Welt. onlineZeitschrift Kunst Medien Bildung | zkmb. https://zkmb.de/sammlung/postdigital-landscapes.

Krajewski, M. (2011): Quasi-Objekte. In H. Maye \& L. Scholz (Eds.), Einführung in die Kulturwissenschaft (pp. 145-187). Fink.

Lacan, J. (1996a). Das Spiegelstadium als Bildner der Ichfunktion. In N. Haas \& H.-J. Metzger (Eds.), Schriften (pp. 61-70). Quadriga (2).

Lacan, J. (1996b). Über eine Frage, die jeder möglichen Behandlung der Psychose vorausgeht. In N. Haas \& H.-J. Metzger (Eds.), Schriften (pp. 61117). Quadriga (2).

Lacan, J. (1998). The seminar of Jacques Lacan, book XX. Encore, On feminine sexuality, the limits of love and knowledge, 1972-1973. Norton.

Latour, B. (2005). Reassembling the social: An introduction to actor-networktheory. Oxford University Press.

Law, J. (2006). Notizen zur Akteur-Netzwerk-Theorie: Ordnung, Strategie und Heterogenität. In A. Belliger \& D. J. Krieger (Eds.): ANThology Ein einfübrendes Handbuch zur Akteur-Netzwerk-Theorie (pp. 429-446). transcript.

Meyer, T. (2017). Next art education: Eight theses future art educators should think about. International Journal of Education through Art, 13(3), 369-384. 
Schulz-Schaeffer, I. (2000). Akteur-Netzwerk-Theorie. Zur Koevolution von Gesellschaft, Natur und Technik. In J. Weyer (Ed.), Soziale Netzwerke. Konzepte und Methoden der sozialwissenschaftlichen Netzwerkforschung (pp. 187-209). Oldenbourg.

Serres, M. (1987). Der Parasit. Suhrkamp.

Serres, M. (1995). Die Legende der Engel. Insel-Verlag.

Tavin, K. (2010). Sites and sinthomes: Fantasmatic spaces of child art in art education. Visual Art Research, 36(2), 49-62.

Vierkant, A. (2011). Image objects (mixed media). https://artievierkant.com/ imageobjects.php.

Vierkant, A. (2018). Interview with Kristin Klein as part of the project PostInternet Arts Education Research on 04-07-2018. University of Cologne, unpublished transcript.

Open Access This chapter is licensed under the terms of the Creative Commons Attribution 4.0 International License (http://creativecommons.org/licenses/ by $/ 4.0 /$ ), which permits use, sharing, adaptation, distribution and reproduction in any medium or format, as long as you give appropriate credit to the original author(s) and the source, provide a link to the Creative Commons license and indicate if changes were made.

The images or other third party material in this chapter are included in the chapter's Creative Commons license, unless indicated otherwise in a credit line to the material. If material is not included in the chapter's Creative Commons license and your intended use is not permitted by statutory regulation or exceeds the permitted use, you will need to obtain permission directly from the copyright holder.

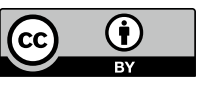

